\title{
TERITORIALITAS DALAM TINJAUAN ILMU ARSITEKTUR
}

\author{
Ratna Dewi Nur'aini' ${ }^{1}$, kaputra² \\ ${ }^{1}$ Program Studi Arsitektur, Fakultas Teknik, Universitas Muhammadiyah Jakarta, Jakarta \\ ${ }^{2}$ Departemen Teknik Arsitektur dan Perencanaan, Fakultas Teknik, Universitas Gadjah Mada, Yogyakarta \\ Email: ratnadewina@ftumj.ac.id
}

\begin{abstract}
Human activities form territorial behavior to achieve their privacy. Theories about territoriality were stated by experts. How do the opinions of experts on territorial theory and how its application in research in the field of Architecture will be discussed in this paper. The method used to explore this theory of territoriality using reference studies. From some expert opinions it can be concluded that territoriality is a territory that has boundaries in the form of fix, semi fix, and non fix elements, which are owned by certain individuals or groups in which there is control behavior to regulate the territory, create privacy and defend themselves from outside intervention. This territoriality theory has been developed and applied in architectural research on micro, meso, and macro scale.
\end{abstract}

Keywords: architecture, control, privacy, territory, territoriality

\begin{abstract}
ABSTRAK
Manusia dalam melakukan aktivitas membentuk perilaku teritorialitas untuk memenuhi kebutuhan privasinya. Teori tentang teritorialitas banyak dikemukakan oleh para ahli. Bagaimana pendapat para ahli tentang teori teritorialitas ini dan bagaimana aplikasinya dalam kajian di bidang Arsitektur akan dibahas dalam tulisan ini. Metode yang digunakan untuk menggali teori tentang teritorilitas ini dengan menggunakan studi referensi. Dari beberapa pendapat para ahli dapat disimpulkan bahwa teritorialitas merupakan teritori yang memiliki batas berupa elemen fix, semi fix, dan non fix, yang dimiliki oleh individu atau kelompok tertentu yang di dalamnya terdapat perilaku kontrol untuk mengatur teritori tersebut, menciptakan privasi dan untuk mempertahankan diri dari intervensi pihak luar. Teori teritorialitas ini banyak dikembangkan dan diaplikasikan dalam beberapa kajian di bidang ilmu Arsitektur baik itu yang berskala mikro, meso, dan makro.
\end{abstract}

Kata kunci: arsitektur, kontrol, privasi, teritori, teritorialitas. 


\section{PENDAHULUAN}

Manusia baik secara individu ataupun berkelompok membutuhkan ruang untuk beraktivitas. Dalam beraktivitas tersebut membentuk perilaku teritorialitas untuk memenuhi kebutuhan privasi sehingga teritorialitas merupakan salah satu unsur arsitektur perilaku. Kajian tentang teritorialitas di bidang ilmu arsitektur banyak dilakukan untuk mengembangkan teori teritorialitas dan aplikasinya.

Teori tentang teritorialitas banyak dikemukakan oleh para ahli seperti Porteous, Pastalan, Lotman, Raffestin, Hall, Lauren, dan lain sebagainya. Bagaimana pendapat para ahli tentang teori teritorialitas ini dan seperti apakah aplikasinya dalam kajian di bidang Arsitektur akan dibahas lebih lanjut dalam tulisan ini.

Kamus Besar Bahasa Indonesia, istilah territory atau "wilayah" diartikan sebagai daerah (kekuasaan, pemerintahan, pengawasan); lingkungan daerah (provinsi, kabupaten, kecamatan). Sedangkan istilah territoriality atau "teritorial" diartikan mengenai bagian wilayah (daerah hukum) suatu negara. Menurut Kamus Merriam, istilah territoriality diartikan sebagai pola perilaku yang terkait dengan pertahanan terhadap suatu wilayah.

Porteous (1977) berpendapat, teritorialitas sebagai batas makhluk hidup yang menentukan kepemilikan terhadap teritori yang didalamnya terdapat suatu kontrol oleh individu ataupun kelompok untuk mempertahankan dari kemungkinan intervensi atau agresi pihak lain. Hal ini diperkuat oleh pendapat Hall (1969) bahwa teritorialitas berhubungan dengan kepemilikan dan tingkat kontrol bahwa penghuni memiliki kuasa atas penggunaan suatu tempat. Teritorialitas berhubungan dengan personalisasi. Personalisasi menurut pendapat Altman (1975) adalah suatu pernyataan kepemilikan individu atau kelompok terhadap suatu tempat melalui tanda-tanda inisial diri baik secara konkrit (fisik) ataupun simbolik (non fisik). Secara konkrit ditandai dengan adanya penempatan (occupancy), dan secara simbolik dengan keterkaitan tempat (attachment) (Brower, 1976).

Laurens (2005) berpendapat bahwa teritorialitas sebagai suatu pola tingkah laku yang merupakan perwujudan egoisme seseorang dikarenakan orang tidak ingin diganggu, atau sebagai perwujudan privasi seseorang. Indikator teritorialitas seperti papan nama, pagar batas, atau papan nama yang mencantumkan kepemilikan atau hak suatu lahan. Teritori menurut Pastalan (1970) merupakan ruang terbatas yang digunakan oleh individu atau kelompok yang dipertahankan sebagai tempat eksklusif. Hal ini berhubungan dengan identifikasi psikologis dengan tempat yang ditandai oleh sikap memiliki dan mengatur objek pada area tersebut. Sedangkan Lotman (1985) dalam Raffestin (2012) menjelaskan bahwa teritorialitas merupakan penataan kembali ruang-ruang dan isinya, yang urutannya dapat ditemukan dalam sistem informasi berdasarkan kultur. Teritori dianggap sebagai ruang informasi dengan sistem penandaan.

Dari beberapa pendapat para ahli tersebut dapat dirangkum tentang pengertian teritorialitas merupakan ruang yang memiliki batas yang dimiliki oleh individu atau kelompok tertentu yang di dalamnya terdapat kontrol untuk mengatur objek area tersebut dan untuk mempertahankan dari intervensi pihak luar (Porteous, 1977; Pastalan, 1970; Lotman, 1985 dalam Raffestin, 2012; Hall, 1969; Lauren, 2005). 


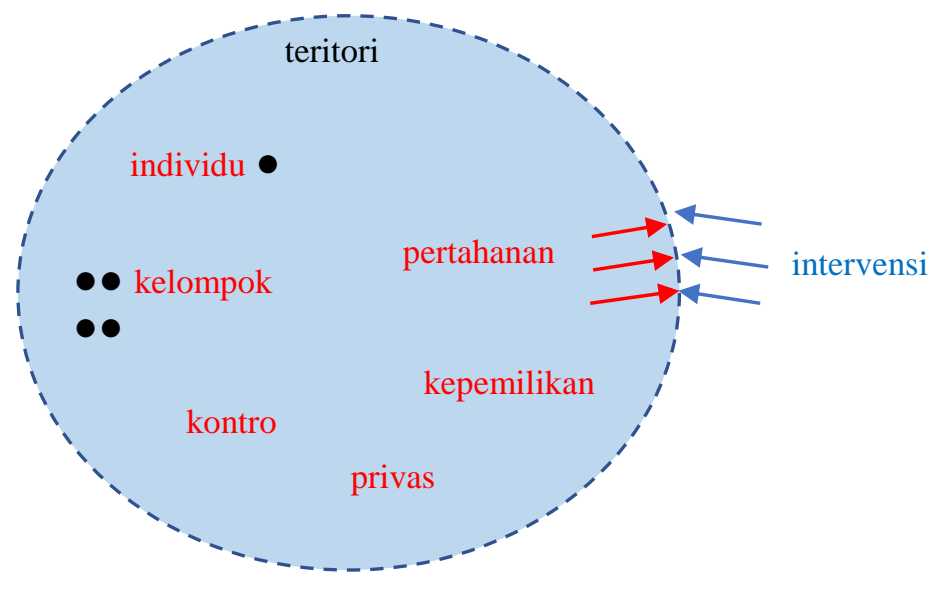

Gambar 1. Skema teritorialitas

(Sumber: Disarikan dari Porteous, 1977; Pastalan, 1970; Lotman, 1985 dalam Raffestin, 2012; Hall, 1969; Lauren, 2005)

\section{Teritorialitas, Privasi, dan Kontrol}

Hall (1969) menyatakan bahwa teritorialitas berhubungan dengan privasi yang berhubungan dengan kepemilikan dan tingkat kontrol bahwa penghuni memiliki kuasa atas penggunaan suatu tempat. Brower (1976) juga menjelaskan bahwa teritorialitas merupakan hubungan individu atau kelompok dengan seting fisiknya, yang dicirikan oleh rasa memiliki dan upaya kontrol terhadap penggunaan interaksi yang tidak diinginkan melalui kegiatan penempatan, mekanisme defensif dan keterikatan. Kontrol teritorial memungkinkan untuk mencapai tingkat privasi dan keintiman yang berbeda dari tingkat tinggi hingga tingkat rendah.

Stea (1965) \& Holahan (1982) dalam Angkasa (1998) menyatakan bahwa teritorialitas merupakan suatu pola tingkah laku yang berhubungan dengan rasa kepemilikan atau hak seseorang atau sekelompok orang pada suatu tempat atau suatu lokasi geografis. Sedangkan menurut Lauren (2005), teritorialitas sebagai suatu pola tingkah laku yang merupakan perwujudan egoisme sebagai perwujudan privasi. Secara geografis, teritorialitas adalah bentuk perilaku spasial (Sack, 1986 dalam Raffestin, 2012). Teritorialitas merupakan aspek khusus perilaku spasial yang pertama kali digunakan dalam hubungan perilaku spasial hewan (Brower, 1976). Perilaku teritorial mempersempit ruang untuk menciptakan lingkungan yang dapat diprediksi dengan rasa dan keamanan yang dialaminya.

Pengertian kontrol lebih lanjut dijelaskan oleh Altman (1975) adalah mekanisme mengatur batas antara orang yang satu dengan lainnya melalui penandaan atau personalisasi untuk menyatakan bahwa tempat tersebut ada yang memilikinya. Namun menurut Brower (1976), teritorialitas bukanlah satu-satunya mekanisme untuk mengendalikan interaksi social, namun juga dapat dikendalikan dengan protokoler dan ritual. Mekanisme defensif menurut Brower (1976) dapat dilakukan melalui berbagai kegiatan seperti: memperjelas batas, memasang penyangga, dan memasang tanda larangan secara menyolok. Mekanisme defensif ini dapat bersifat terang-terangan, misalnya dengan pengawasan langsung terus menerus terhadap suatu pangkalan militer, namun dapat juga dilakukan secara halus dengan menjauhkan diri dari gangguan yang tidak diinginkan, misalnya 
Teritorialitas dalam Tinjauan ... (Ratna/ hal 12-22)

ruang tamu didesain agar pandangan tamu tidak langsung tertuju ke dalam ruang tidur. Selain itu bisa dilakukan dengan meninggalkan tanda-tanda pengenal diri (personalisasi), misalnya meninggalkan buku di atas meja di dalam ruang baca perpustakaan. Jadi mekanisme defensif dapat juga dilakukan dengan kegiatan menghindar dan mencegah (preventif) dari intervensi pihak lain yang ditandai dengan adanya unsur-unsur penempatan dan keterikatan. Pendapat lain menurut Sack (1986) dalam Raffestin (2012), teritorialitas pada manusia dipahami sebagai strategi spasial untuk mempengaruhi atau mengendalikan sumber daya alam dan manusia, dapat dihidupkan dan dimatikan. Hubungan antara teritorialitas, privasi, dan kontrol dapat dilihat pada gambar di bawah ini.

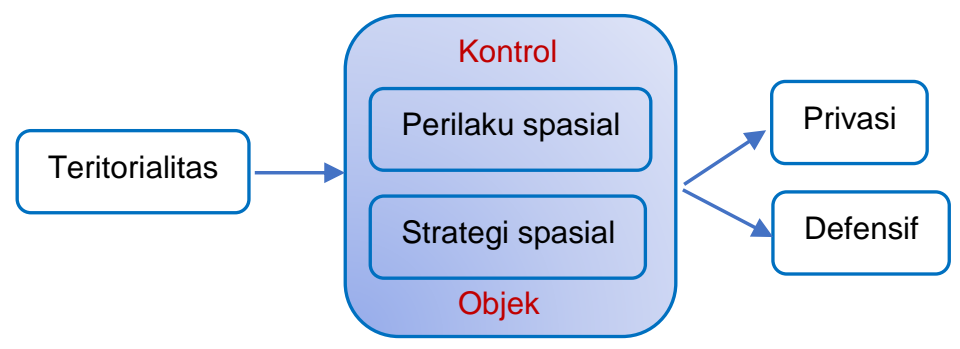

Gambar 2. Teritorialitas, privasi, dan kontrol

(Sumber: Disarikan dari Hall, 1969; Laurens, 2005; Sack, 1986 dalam Raffestin, 2012;

Brower, 1976; Altman, 1975)

Tabel 1. Unsur-unsur yang berhubungan dengan Teritorialitas

\begin{tabular}{|c|c|c|c|c|c|c|c|c|c|}
\hline & Batas & Teritori & Bertahan & Kontrol & $\begin{array}{c}\text { Perilaku } \\
\text { spasial }\end{array}$ & Kepemilikan & Intim & Privasi & Eksklusi \\
\hline Hall, 1969 & - & $\sqrt{ }$ & - & $\sqrt{ }$ & - & $\sqrt{ }$ & - & $\sqrt{ }$ & - \\
\hline Pastalan, 1970 & $\sqrt{ }$ & - & $\sqrt{ }$ & $\sqrt{ }$ & - & $\sqrt{ }$ & - & - & $\sqrt{ }$ \\
\hline Altman, 1975 & $\sqrt{ }$ & $\sqrt{ }$ & - & $\sqrt{ }$ & - & $\sqrt{ }$ & - & - & - \\
\hline Brower, 1976 & - & - & - & $\sqrt{ }$ & $\sqrt{ }$ & - & $\sqrt{ }$ & $\sqrt{ }$ & - \\
\hline Porteous, 1977 & $\sqrt{ }$ & $\sqrt{ }$ & $\sqrt{ }$ & $\sqrt{ }$ & - & - & - & - & $\sqrt{ }$ \\
\hline Lotman, 1985 & - & - & - & $\sqrt{ }$ & - & - & - & - & - \\
\hline Sack, 1986 & - & - & - & $\sqrt{ }$ & $\sqrt{ }$ & - & - & - & - \\
\hline Lauren, 2005 & - & - & - & - & $\sqrt{ }$ & $\sqrt{ }$ & - & $\sqrt{ }$ & - \\
\hline
\end{tabular}

(Sumber: Disarikan dari Hall, 1969; Pastalan, 1970; Brower,1976; Porteous, 1977; Lotman, 1985; Sack, 1986; Altman (1975); dan Lauren, 2005)

\section{METODE}

Metode yang digunakan pada kajian ini adalah studi literature/referensi, tujuannya untuk menggali teori tentang teritorilitas kajian. Dari beberapa pendapat para ahli akan disimpulkan terkait teritori yang memiliki batas seperti elemen fix, semi fix, dan non fix, yang dimiliki oleh individu atau kelompok tertentu yang di dalamnya terdapat perilaku kontrol untuk mengatur teritori tersebut, serta dapat menciptakan privasi dan bertujuan untuk mempertahankan diri dari intervensi pihak luar. 


\section{HASIL DAN PEMBAHASAN}

Altman (1975) dan Hall (1969)
mengklasifikasikan teritori menjadi tiga,
yaitu:

1) Teritori primer (primary territory). Pada teritori primer ini rasa kepemilikan individu atau suatu kelompok sangat tinggi, cenderung dimiliki secara permanen. Pemiliknya memiliki control secara penuh pada area tersebut, gangguan merupakan suatu hal yang serius menjadi perhatian. Contoh yang termasuk dalam teritori primer adalah rumah dan kantor.

2) Teritori sekunder (secondary territory). Teritori sekunder ini tidak dimilki oleh individu atau suatu kelompok, tetapi sering digunakan dan orang lain pun diperbolehkan menggunakan area tersebut. Rasa memiliki pada teritori sekunder ini tergolong tingkat sedang. Pengguna area teritori sekunder dilihat sebagai pengguna yang berkualitas, dapat dipersonalisasikan sampai batas dan periode waktu tertentu. Contoh area pada tipe teritori sekunder ini adalah ruang kelas, kantin, perpustakaan, hotel, loket antrian tiket, museum, dan pacuan kuda.

3) Teritori publik (public territory). Teritori publik tidak dimiliki oleh individu ataupun suatu kelompok. Rasa kepemilikan pada teritori ini tergolong rendah dan sangat sulit mengontrol area ini. Area teritori publik digunakan oleh sejumlah orang yang sangat banyak. Setiap individu memiliki hak yang sama pada area ini, contohnya pantai, mal, taman, dan ruang tunggu.

Disamping itu Brower mengklasifikasikan teritori ke dalam empat tipe, yaitu:

1) Teritori personal. Teritori ini dikontrol secara individu atau kelompok. Anggota kelompok mempunyai ikatan hubungan yang sangat dekat seperti hubungan karena perkawinan atau pertalian darah.
Contoh yang termasuk dalam kategori teritori primer adalah rumah dan kamar. Hak kepemilikan sangat kuat dan dilindungi oleh hukum. Tanda-tanda kepemilikan personal bersifat lebih pribadi dan sering ditandai dengan identitas pemilik seperti foto keluarga dan piagam.

2) Teritori komunitas. Teritori ini dikontrol oleh kelompok yang anggotanya kadang-kadang berubah, tetapi setiap anggota telah melalui proses penyaringan dan sering dilakukan upacara pelantikan dalam penerimaan anggota tersebut. Contoh dalam teritori komunitas adalah jamaah masjid dan pelajar. Orang lain yang berada pada teritori ini tidak dianggap sebagai suatu gangguan selama larangan dan kontrol tidak dilanggar.

3) Teritori masyarakat. Teritori ini dikontrol oleh masyarakat umum dan terbuka untuk umum seperti jalan raya, ruang tunggu, dan ruang pertunjukan. Larangan dan kontrol dilakukan melalui peraturan atau norma yang berasal dari masyarakat berdasarkan jenis kelamin, perbedaan usia, dan perbedaan ras. Contoh kaum wanita di Timur Tengah mengenakan cadar apabila berada di tempat umum. Tandatanda untuk mengenali teritori ini cukup jelas dan nyata dan mempunyai standar tertentu sebagai panduan bagi orang asing.

4) Teritori bebas. Teritori ini tidak memiliki penghuni tetap dan keberadaan subjek tidak di bawah larangan atau kontrol suatu pihak tertentu. Teritori ini dicirikan oleh tidak terdapatnya tanda-tanda territorial, oleh karena itu larangan atau kontrol yang muncul disebabkan eksploarasi dan imajinasi penghuninya, contoh hutan lebat dan pantai yang sepi. 
Teritorialitas dalam Tinjauan ... (Ratna/ hal 12-22)

Beberapa penelitian yang berhubungan dengan teritorialitas sudah banyak dilakukan. Pada tulisan ini akan dideskripsikan beberapa penelitian yang berhubungan dengan teritorialitas di bidang ilmu Arsitektur. Beberapa penelitian berikut ini mengambil lokasi di Indonesia, sebagai berikut:

Angkasa (1998) melakukan penelitian tentang teritorialitas pada kawasan permukiman rakit di muara sungai. Teritorialitas yang berlangsung di permukiman rakit meliputi perilaku menghindar, mencari teman dan mebuat batas fisik. Ketiga perilaku tersebut disebabkan oleh situasi lingkungan yang dipersepsikan oleh orang rakit sebagai suatu ancaman atau gangguan. Fakorfaktor yang menyebabkan terjadinya teritorialitas tersebut adalah:

1) Situasi lingkungan, berupa: frekuensi yang tinggi lalu lintas sungai; ombak sungai yang besar; kehadiran peguasa setempat; dan banyaknya orang yang melewati kawasan permukiman.

2) Latar belakang orang rakit, yaitu kaum pendatang dari pedalaman; menempati secara tidak sah; bertempat tinggal di rumah yang sangat rentan terhadap gangguan ombak dan benturan kapal; tidak memiliki rumah lain; pekerja di sektor informal; mudah was-was dan curiga.

3) Proses bermukim orang rakit, yaitu memilih sungai yang lebih tenang dan tersembunyi; mengaitkan permukiman mereka dengan permukiman di darat; menandai teritori dengan patok atau perahu.

Penelitian tentang teritorialitas pada permukiman padat di perkotaan yang dilakukan oleh Burhanuddin (2010) menjelaskan karakteristik teritorialitas ruang pada permukiman padat yang memiliki batas fisik berupa bangunan-bangunan rumah di sekelilingnya dapat dilihat dari pengaruh komponen fix di dalam ruang yang berfungsi sebagai magnet timbulnya aktivitas manusia seperti warung sehingga menimbulkan reaksi kesepakatan masyarakat untuk menyediakan tempat-tempat duduk sebagai komponen semi-fix. Diagram teritorialitas pada permukiman padat di dapat dilihat pada gambar di bawah ini.

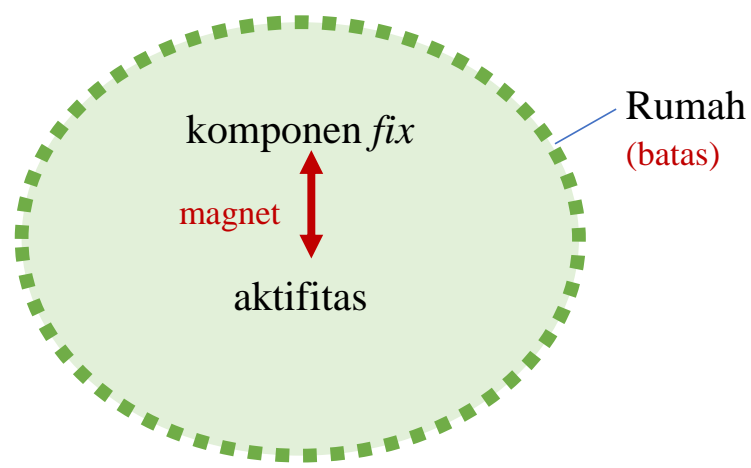

Gambar 3. Teritorialitas pada permukiman padat di perkotaan (Sumber: Disarikan dari Burhanuddin, 2010)

Putri, dkk (2012) melakukan penelitian tentang pendekatan teritori pada fleksibilitas ruang dalam tradisi sinoman dan biyada di Malang. Hubungan kedekatan kekerabatan tidak berpengaruh terhadap pembentukan perluasan teritori, tetapi perbedaan pola pembentukan teritori dipengaruhi faktor ketersediaan ruang terbuka yaitu pelataran belakang rumah. Faktor ketersediaan ruang terbuka menjadikan batas teritori yang 
berbeda. Objek amatan yang memiliki ruang terbuka, teritorinya terbentuk dengan batasbatas elemen semi-fix dan elemen non-fix. Sedangkan yang tidak memiliki ruang terbuka, teritorinya didominasi dengan batas elemen fix berupa dinding-dinding pembatas ruang.

Putrie dan Maslucha (2013) meneliti tentang masjid dalam lingkungan pesantren yang memiliki teritori khusus jika dibandingkan dengan masjid secara umum. Teritori primer dari masjid yang meliputi mihrab dan ruang sholat utama, terikat oleh aturan (fiqih) dan etika (adab) aturan tata perilaku di dalam masjid. Semakin rendah tingkatan teritori masjid yaitu teritori publik, maka sifatnya semakin umum (profan), dan semakin tinggi tingkatan teritorinya yaitu teritori primer, maka sifatnya menjadi lebih sakral. Kekhasan pola perilaku keruangan disebabkan oleh adanya adab terhadap masjid dan adab terhadap kyai sebagai pemimpin masjid dan pesantren. Perilakuperilaku ini membentuk pola karena telah menjadi tradisi atau kebiasaan setempat yang menjadi perwujudan yang khas terhadap adab. Pola perilaku ini juga membentuk teritori-teritori yang khas di masjid tersebut. Skema teritori masjid di dalam pesantren dapat dilihat pada gambar di bawah ini.

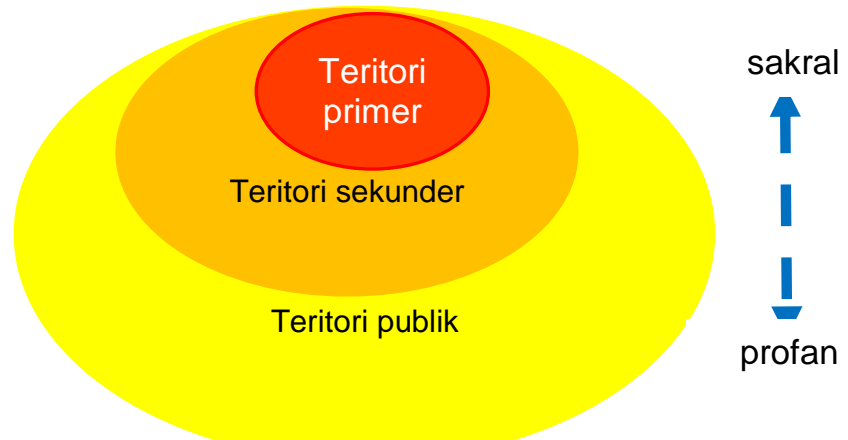

Gambar 4. Teritori masjid di dalam pesantren (Sumber: Disarikan dari Putrie dan Maslucha, 2013)

Kasman, dkk (2015) meneliti tentang teritorialitas masyarakat perumahan menengah ke bawah di Bandung menghasilkan 3 (tiga) pola umum ekspansi territorial, sebagai berikut:

1) pola ekspansi yang dilakukan pada batas teritori legal.

2) pola ekspansi pada sisi luar batas teritori legal.

3) pola ekspansi pada koridor/gang sebagai teritori publik.

Pola ekspansi dipengaruhi oleh 3 (tiga) aspek pembentuk teritorialitas pada perumahan, antara lain aspek legalitas, aspek aktivitas, dan aspek persepsi. Aspek tersebut juga tidak lepas dari karakteristik penghuni atau masyarakat itu sendiri.
Aspek persepsi masyarakat memiliki andil yang paling besar dalam hal ekspansi teritorial karena adanya rasa memiliki yang didasari oleh kedekatan antar masyarakat tersebut sehingga rasa sungkan untuk melakukan ekspansi tergolong kecil.

Poedjowibowo, dkk (2016) melakukan penelitian tentang teritorialitas pada permukiman di atas air. Ditemukan jenis teritorialitas keluarga dan teritorialitas lingkungan/desa. Selain teritorialitas bersifat primer, sekunder dan publik, juga ditemukan teritorialitas bersifat ganda, sebagai berikut:

1) Teritorialitas keluarga bersifat ganda seperti diaruma, dapurang, halaman rumah bisa bersifat primer, sekunder 
Teritorialitas dalam Tinjauan ... (Ratna/ hal 12-22)

dan publik tergantung dari kegiatan yang berlangsung.

2) Teritorialitas lingkungan/desa bersifat ganda seperti dermaga pelabuhan, ladang rumput laut dan rakit tempat mencari ikan.

Elemen-elemen teritorialitas keluarga meliputi:

1) Elemen teritorialitas primer keluarga: selasar/dinding samping, tatambe, benteng, area tambatan perahu, karamba, lintasan perahu, tirai, dinding, balawa, dodika, lemari, alat memasak, meja dan kursi makan.

2) Elemen teritorialitas sekunder keluarga: jalan, selasar/dinding samping serta tatambe, sofa, meja, kursi, TV, hiasan dinding bernuansa Islami, dodika, lemari, alat memasak, meja dan kursi makan, dek bangunan.

3) Elemen teritorialitas publik keluarga: jalan, selasar/dinding samping serta tatambe, benteng, area tambatan perahu, karamba dan lintasan perahu.
Elemen-elemen teritorialitas desa/ lingkungan meliputi:

1) Elemen teritorialitas primer desa: piranti menanam rumput laut seperti jangkar, pelampung, tali dan rumput laut, tempat menangkap ikan di tengah laut berupa rakit yang terdiri atas pelampung, rumah jaga, pelampung, tali dan jangkar serta pajeko dan perlengkapan menangkap ikan.

2) Elemen teritorialitas sekunder desa: dermaga dan perahu tertambat, bangunan gedung serbaguna, tempat pemakaman.

3) Elemen teritorialitas publik desa: batas desa, dermaga dan perahu tertambat, masjid, piranti menanam rumput laut seperti jangkar, pelampung, tali.

Pemaknaan teritorialitas pada permukiman di atas air ini sangat dipengaruhi oleh budaya hidup suku laut, yakni perlunya ruang untuk lalu lintas dan tempat tambat perahu serta karamba sebagai tempat budi daya ikan juga pandangan kepemilikan bersama terhadap wilayah perairan. Diagram teritorialitas ganda pada permukiman di atas air dapat di dilihat pada gambar di bawah.

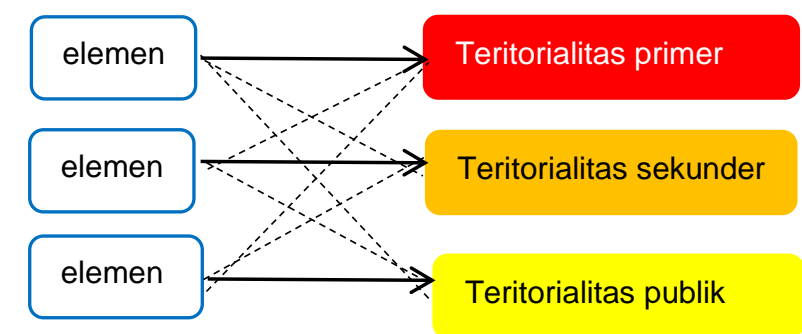

Gambar 5. Teritorialitas ganda pada permukiman di atas air (Sumber: Disarikan dari Poedjowibowo, dkk., 2016)

Bawembang dkk. (2017) mengamati penerapan seting teritori dalam ruang publik pada sebuah kawasan kampung Cina yaitu: (1) teritori primer di area ruko bagian toko; (2) teritori sekunder berada pada area pedestrian, area parkir depan ruko, tempat ibadah; dan (3) teritori publik dapat ditemukan di seluruh bagian kawasan kampung baik di area pertokoan, pedestrian, area parkir, jalan, tempat ibadah karena dapat diakses setiap orang namun aktivitasnya diatur norma dan aturan yang berlaku. Diagram seting teritori pada kawasan kampung Cina ini dapat dilihat dalam gambar di bawah. 


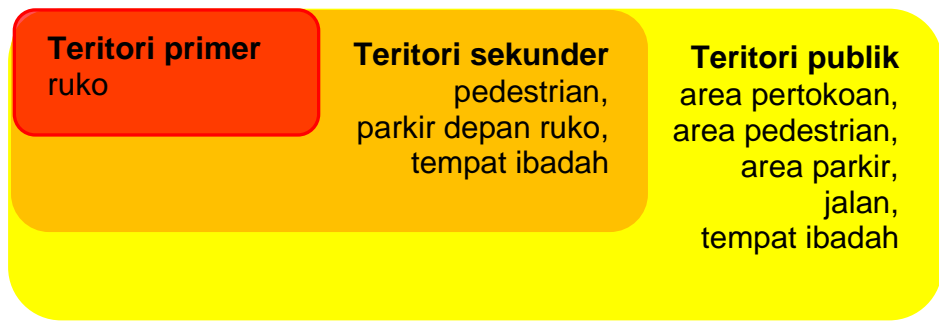

Gambar 6. Seting teritori pada kawasan kampung Cina (Sumber: Disarikan dari Bawembang dkk, 2017)

Kridarso (2018) membagi teritori rumah produksi batik di Pekalongan menjadi 3 (tiga) yaitu: (1) zona berhuni yang bersifat privat merupakan teritori ruang yang ditempati khusus oleh penghuni, ditandai secara simbolik dengan penataan perabot atau dapat disebut sebagai teritori tertutup; (2) zona bekerja yang bersifat semi publik merupakan teritori ruang yang digunakan oleh penghuni dan pekerja ditandai secara nyata dalam batasan ruang atau dapat disebut sebagai teritori terbatas; (3) zona bersama (berhuni dan bekerja) bersifat publik merupakan teritori yang dapat diakses oleh penghuni, karyawan dan tamu atau disebut sebagai teritori terbuka. Diagram teritori rumah produksi ini dapat dilihat pada gambar di bawah.

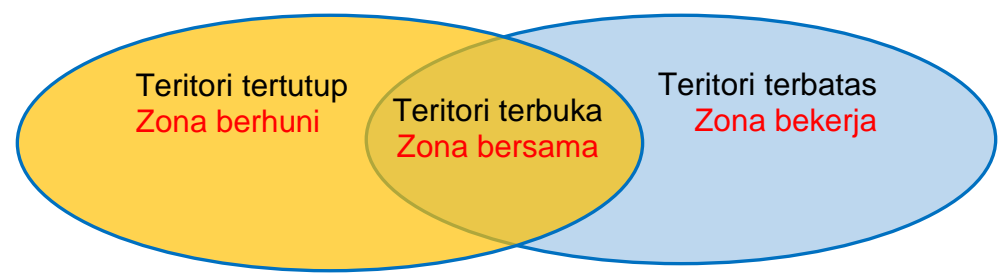

Gambar 7. Teritori pada rumah produksi (Sumber: Disarikan dari Kridarso, 2018)

Tabel 2 berikut ini merangkum beberapa contoh penelitian tentang teritorialitas di bidang ilmu Arsitektur yang mengambil lokasi di Indonesia: 
Tabel 2. Penelitian tentang Teritorialitas

\begin{tabular}{|c|c|c|}
\hline Peneliti & Fokus & Hasil \\
\hline Angkasa, 1998 & $\begin{array}{l}\text { Teritorialitas pada kawasan } \\
\text { permukiman rakit. }\end{array}$ & $\begin{array}{l}\text { Teritorialitas meliputi perilaku menghindar, } \\
\text { mencari teman dan mebuat batas fisik. }\end{array}$ \\
\hline Burhanuddin, 2010 & $\begin{array}{l}\text { Teritorialitas pada } \\
\text { permukiman padat. }\end{array}$ & $\begin{array}{l}\text { Teritorialitas merupakan pengaruh elemen fix } \\
\text { ruang sebagai magnet aktivitas yang } \\
\text { menimbulkan reaksi masyarakat menyediakan } \\
\text { fasilitas berupa elemen semi-fix. }\end{array}$ \\
\hline Putri dkk., 2012 & $\begin{array}{l}\text { Teritori ruang dalam tradisi } \\
\text { sinoman dan biyada. }\end{array}$ & $\begin{array}{l}\text { Pola teritori dipengaruhi faktor ruang terbuka } \\
\text { (pelataran rumah). }\end{array}$ \\
\hline Putrie \& Maslucha, 2013 & $\begin{array}{l}\text { Teritori masjid di dalam } \\
\text { pesantren }\end{array}$ & $\begin{array}{l}\text { Teritori primer meliputi mihrab dan ruang sholat } \\
\text { utama, terikat oleh fiqih dan adab perilaku di } \\
\text { dalam masjid. Teritori publik bersifat profan, dan } \\
\text { teritori primer bersifat sakral. }\end{array}$ \\
\hline Kasman dkk., 2015 & $\begin{array}{l}\text { Teritorialitas masyarakat } \\
\text { perumahan menengah ke } \\
\text { bawah. }\end{array}$ & $\begin{array}{l}\text { Pola ekspansi teritorial dipengaruhi aspek } \\
\text { legalitas, aspek aktivitas, dan aspek persepsi. }\end{array}$ \\
\hline Poedjowibowo dkk., 2016 & $\begin{array}{l}\text { Teritorialitas pada } \\
\text { permukiman di atas air }\end{array}$ & $\begin{array}{l}\text { Teritorialitas keluarga dan teritorialitas } \\
\text { lingkungan/desa. Teritorialitas ganda. }\end{array}$ \\
\hline Bawembang dkk., 2017 & $\begin{array}{l}\text { Teritori pada kawasan } \\
\text { kampung Cina. }\end{array}$ & Teritori primer, teritori sekunder dan teritori publik. \\
\hline Kridarso, 2018 & Teritori pada rumah produksi. & $\begin{array}{l}\text { Teritori tertutup, teritori terbatas, dan teritori } \\
\text { terbuka. }\end{array}$ \\
\hline
\end{tabular}

\section{SIMPULAN}

Dari beberapa pendapat para ahli dapat disimpulkan bahwa teritorialitas merupakan teritori yang memiliki batas berupa elemen fix, semi fix, dan non fix, yang dimiliki oleh individu atau kelompok tertentu yang di dalamnya terdapat perilaku kontrol untuk mengatur teritori tersebut, menciptakan

\section{DAFTAR RUJUKAN}

Altman, I (1975). The Environment and Social Behavior. Brooks/Cole Publishing Company, California.

Altman, I, Rapoport, A, \& Wohlwill, Joachim F (1980). Human Behavior and Environment: Advances in Theory and Research, Volume 4: Environment and Culture, Plenum Press, New York and London.

Angkasa, Z. (1998). Teritorialitas pada Kawasan Permukiman Rakit di Muara Sungai Ogan Palembang. privasi dan untuk mempertahankan diri dari intervensi pihak luar.

Teori teritorialitas ini banyak dikembangkan dan diaplikasikan dalam beberapa kajian di bidang ilmu Arsitektur baik itu yang berskala mikro, meso, dan makro.
Bawembang, E. N. dkk. (2017). "Teritori Dalam Ruang Publik Masyarakat Kampung

Cina Di Kota Manado", Jurnal Arsitektur Daseng Unsrat, Vol. 6, No. 1 , pp. $32-42$.

Brower, S. N. (1976). Territory in Urban Settings, dalam Altman, I, Rapoport, A, \& Wohlwill, Joachim F, 1980, 
Human Behavior and Environment: Advances in Theory and Research, Volume 4: Environment and Culture, Plenum Press, New York and London.

Burhanuddin (2010). Karakteristik Teritorialitas Ruang Pada Permukiman Padat di Perkotaan. Jurnal Ruang, Vol. 2, No. 1, Maret 2010, pp. $39-46$.

Hall, T. E. (1969). The Hidden Dimension. Doubleday Anchor Book Inc.

Holahan, C. J. (1982) Environmental Psychology. New York: Random House.

Kamus Besar Bahasa Indonesia online https://typoonline.com/kbbi/teritorial diakses tanggal 20 Februari 2019.

Kamus Merriam online https://www.merriam-webster.com diakses tanggal 20 Februari 2019.

Kasman, dkk. (2015). Teritorialitas Masyarakat Perumahan Menengah ke Bawah Studi Kasus: Perumahan Sukaluyu, Cibeunying Kaler, Bandung, Prosiding Temu IImiah IPLBI 2015

Kridarso, Etty R. (2018). Teritori Ruang Pada Rumah Produktif Batik Di Kauman,

Pekalongan - Jawa Tengah, Kota Layak Huni Urbanisasi dan Pengembangan Perkotaan : 99 104.

Laurens, J. M. (2005), Arsitektur dan Perilaku Manusia, Grasindo, PT Gramedia

Pastalan (1970). Privacy, Territoriality, and Personal Space-Proxemic Theory, in Lang, Jon., 1987. Creating Architectural Theory, Van Nonstrand Reinhold, New York.

Poedjowibowo, D. dkk. (2016), Teritorialitas Pada Permukiman Suku Bajo Di
Desa Tumbak (Studi Kasus Permukiman Diatas Air), Jurnal Arsitektur DASENG UNSRAT Manado Vol. 5 No. 2 (2016)

Porteous, J. Douglas (1977). Environment \& Behavior: Planning and Everyday Urban Life, University of Victoria, British Columbia, Addison-Wesley Publishing Company.

Pratama, G. N. I. P., \& Sumarjo, H. (2018). Aksesibilitas Tata Letak Elevator Penumpang Gedung Kantor Pusat Layanan Terpadu (KPLT) Fakultas Teknik UNY. INformasi dan Ekspose hasil Riset Teknik Slpil dan Arsitektur, 14(1), 26-35.

Putri, dkk. (2012) Pendekatan Teritori Pada Fleksibilitas Ruang Dalam Tradisi Sinoman Dan Biyada Di Dusun Karang Ampel Malang, Dimensi (Journal Of Architecture And Built Environment), Vol. 39, No. 2, December 2012, 65-76 ISSN 0126219X

Putrie, Y. E. dan Maslucha, L (2013). Seting Perilaku Dan Teritorialitas Ruang Sebagai Perwujudan Adab Di Masjid Gading Pesantren Kota Malang, Jurnal el Harakah, Vol.15 No.2, pp. $185-198$.

Raffestin, Claude (2012). Space, territory, and territoriality, Environment and Planning D: Society and Space, Vol. 30, pp. $121-141$.

Stea, D. (1965) Territoriality, The Interior Aspect: Space, Territory and Human Movements. Landscape 